International Neuropsychiatric Disease Journal

9(3): 1-9, 2017; Article no.INDJ.33703

ISSN: 2321-7235, NLM ID: 101632319

SCIENCEDOMAIN international

www.sciencedomain.org

\title{
Dream Anxiety in Patients with Rapid Eye Movement Dependent Obstructive Sleep Apnea Syndrome
}

\author{
Ece Yazla ${ }^{1^{*}}$, Mustafa Bilici $^{2}$ and Zerrin Pelin ${ }^{3}$ \\ ${ }^{1}$ Department of Psychiatry, Hitit University, Çorum, Turkey. \\ ${ }^{2}$ Department of Psychology, Istanbul Gelişim University, İstanbul, Turkey. \\ ${ }^{3}$ Faculty of Health Sciences, Hasan Kalyoncu University, Gaziantep, Turkey.
}

Authors' contributions

This work was carried out in collaboration between all authors. Authors MB and ZP designed the study. Authors $Z P, M B$ and $E Y$ involved in acquisition of data. Authors $E Y$ and $M B$ analyzed and interpreted the data. Authors $E Y$ and MB drafted the manuscript. Author EY involved in critical revision of the manuscript for important intellectual content. Authors $M B$ and $E Y$ performed the statistical analysis. Authors EY, ZP and MB involved in administrative, technical and material support. Author EY supervised the study. All authors read and approved the final manuscript.

Article Information

DOI: $10.9734 /$ INDJ/2017/33703

Editor(s):

(1) Elena Cecilia Rosca, Department of Neurology, University of Medicine and Pharmacy, Romania.

Reviewers:

(1) Ayhan Goktepe, Selcuk University, Konya, Turkey.

(2) Geraldo Rizzo, Hospital Moinhos de Vento, Brazil. (3) Elisabeth Meyer, Federal University of Rio Grande do Sul, Brazil. (4) Tetsuo Harada, Graduate School of Integrated Arts and Sciences, Kochi University, Japan. (5) José Carlos Souza, Mato Grosso do Sul State University, Brazil. (6) Franco Gemignani, University of Parma, Italy. Complete Peer review History: http://www.sciencedomain.org/review-history/19254

Original Research Article

Received 26 $6^{\text {th }}$ April 2017

Accepted $27^{\text {th }}$ May 2017

Published $30^{\text {th }}$ May 2017

\section{ABSTRACT}

Aims: The aim of this study is to investigate the effect of the breathing disorders that arise during sleep and are predominantly observed in Rapid Eye Movement (REM) phase onto the dreams which have negative effects on daily life. While doing this, we also investigated differences between the REM dependent and non REM dependent obstructive sleep apnea syndrome groups in terms of some sociodemographic and clinical characteristics.

Methods: Seventy patients who had got the diagnosis of obstructive sleep apnea syndrome (OSAS) according to American Academy of Sleep Medicine (AASM) were included into the study. Twenty of them were selected from those who had REM dependent OSAS.

Results: No significant difference was observed on dream anxiety levels between the groups 
$(p=0,27)$. Dream anxiety level was not found significantly related to clinical characteristics. We determined that the arousal index of non REM dependent OSAS group was significantly higher than that of REM dependent group $(p<0,05)$.

Conclusion: Because of arousals, a rise in the frequency of remembering dreams in the non REM dependent group may also have an effect on increased dream anxiety. Probably this fact might have caused us not to find any differences with the REM dependent group which is accepted to have higher dream anxiety.

Keywords: Dream recall; REM dependent obstructive sleep apnea; obstructive sleep apnea syndrome and dream recall.

\section{INTRODUCTION}

Dreams are roughly defined as any mental activities occurring during sleep. It is known that some differences in electrical, chemical and metabolical activities occur in brain during Rapid Eye Movement (REM) and Non Rapid Eye Movement (NREM) phases of sleep which may be related to the differences between NREM and REM dreams. Reports from REM sleep awakenings are typically longer, vivider, more motorically animated, more emotionally charged and less related to waking life in comparison with NREM reports [1].

Nightmares which are defined as frightening dreams that awakens the sleeper also occur during the REM phase of sleep. Bad dreams or anxiety dreams are sometimes distinguished from nightmares by the fact that the person does not awaken during the dream but recalls the disturbing content upon awakening later. Another aproach says what is more important is how distressing the dream is to the person when awake [2].

Sleep disorders which damage to the sleep structure and integrity are also thought to cause to some changes in dream reports [3]. Obstructive Sleep Apnea Syndrome (OSAS) is one of the most common and important disorders of sleep and diagnosed by demonstrating a sufficient number of obstructive apneas or obstructive hypopneas [4]. There are a number of studies about nightmare frequencies and bad dreams in OSAS patients but results do not reveal any clear evidence about relationship between OSAS severity and emotional content of dreams [5-7].

The aim of this study is to investigate the effect of the breathing disorders that arise during sleep and that are predominantly observed in REM phase onto the dreams which create anxiety and have negative effects on daily life.

\section{METHODS}

\subsection{Participants}

The patients who had got the diagnosis of OSAS according to American Academy of Sleep Medicine (AASM) criteria as a result of clinical evaluations and polysomnographic inspections performed in the Department of Sleep Disorders in Erenkoy Neurolopsychiatric Diseases Education and Research Hospital were included into the study.

Before selecting the patients and following the planning state of the study, the ethical approval was provided by Erenkoy Neuropsychiatric Diseases Education and Research Hospital Ethical and Education Planning Committee. The patients who were convenient for including to the study read, understood and signed the informed consent forms voluntarily.

The group selected for the study contained twenty REM dependent OSAS (ROSAS) patients and fifty non REM dependent or control OSAS (COSAS) patients. ROSAS diagnosis was made based on the criteria of American Academy of Sleep Medicine (AASM 2007) [8], and the criteria of ROSAS was accepted as REM apnea hypopnea index $(\mathrm{AHI}) /$ non-REM $\mathrm{AHI} \geq 2$ and non-REM AHI $<15$ [9].

Some patient groups listed below were excluded from the study:

- the patients younger than eighteen or older than seventy five,

- the patients who did not accept to participate in the study,

- the patients who we fixed the presence of any psychiatric or neurologic disorders in our medical evaluation,

- the patients who were under regular pharmacologic treatment due to these disorders, 
- the patients who had been diagnosed as narcolepsy or a psychiatric disorder that had psychotic characteristics in the past,

- the patients who had a story about addiction to or abusing of alcohol or any substance,

- the patients who had been applied Continious Positive Airway Pressure (CPAP) treatment once upon a time in the past.

Between the dates of 30.09 .2010 and 25.08.2011, the patients from those who had been presumed to be OSAS as a result of clinical evaluations performed in the Clinic of Sleep Disorders were applied Polysomnography (PSG) throughout a night. Their PSG records were scored by the experienced doctors working in the clinic. The first twenty patients taken from those who all met both the ROSAS criterias and the inclusion criterias together with the first fifty patients taken from those who all met the COSAS criterias and also the inclusion criterias according to the clinical evaluation and PSG report were included into the study after they had given their signed informed consents.

\subsection{Materials and Procedure}

\subsubsection{Polysomnography}

PSG data were recorded by a computerized system (Embla N7000). This included 6 EEG channels (C4-A1, C3-A2, O1-A2, F4-A1, F3-A2), bilateral electro-oculograms (EOG), one submental electromyogram (EMG) and electrocardiography (ECG). Airflow was measured using a nasal canula. Respiratory effort was assessed by inductance pletysmography and oxygen saturation was recorded by a transcutaneous finger pulse oximeter. The sleep structure was analyzed through manuel scoring, following the standard procedure defined by AASM. Obstructive apnea, hyponea events were considered to be those with a clear decrease ( $>50 \%$ ) of respiratory flow from baseline or a clear respiratory flow reduction that did not meet above criterion but was associated with either an oxygen desaturation of $>3 \%$ or an arousal. The sleep parameters used were total time analyzed, total sleep time (TST), sleep latency to first 2 minutes of unbroken sleep, REM latency from sleep onset, times in N1, N2, N3 and REM as percentages of total sleep time, apnea-hypopnea index $(\mathrm{AHI})$, mean apnea duration, lowest oxygen saturation, oxygen desaturation index (ODI), longest apnea duration, periodic limb movements index (PLMI) and arousal index accepted as the sum of PLMI and AHI.

\subsubsection{Evaluation questionnaire}

It is the data form in which some information about the patient for instance some sociodemographic variants of them such as age, gender, marital status, length of education, employment status and some measures belonging to them such as body mass index, waist circumference and neck circumference are recorded.

\subsubsection{Epworth sleepiness scale}

It was developed by Johns in 1991 [10]. The validity and reliability studies of the scale to its Turkish version were conducted by Agargun et al in 1999 [11]. It is an eight item self report measure of excessive daytime sleepiness. Respondents indicate on a four-point Likert type scale $(0=$ never, $3=$ high chance) the likelihood that they will "doze off or fall asleep" in eight different conditions. Responses are summed to yield a total score from 0 to 24 , with higher scores indicating greater sleepiness during common daily activities.

\subsubsection{Van dream anxiety scale}

The scale has been developed by Agargun et al. The validity and reliability studies for the scale have been performed on patients with nightmare disorder. It is a scale that is easy for subjects to use and for clinicians to provide a longitudinal assessment of dream anxiety [12]. It consists of seventeen self-rated questions. Four questions are used only for clinical information. Twelve questions are concerned with nightmare, fear of sleeping because of anticipated nightmare, trouble sleeping, dream recall frequency, sleepiness, morning anxiety, occupational distress, familial distress, social distress, psychological disturbances and memory concentration problems. One question is related to autonomic hyperactivity and consists of twelve symptoms. Thus, thirteen question scores are summed to yield a global score.

\subsubsection{Statistical analysis}

In this study statistical analysis were performed by utilizing Statistical Package for the Social Sciences (SPSS) 18. While comparing sociodemographic characteristics of the two groups, chi-square test was used. Independent $t$ test in addition to descriptive statistical factors (mean and standard deviation) were used in 
order to compare dream anxiety levels, ages and polysomnographic parameters. In order to investigate the effects of age and gender variables on dream anxiety levels, which were defined as significantly different between the groups in the $t$ test, co-variance analysis (ANCOVA) was applied. So as to find out the relations of clinical characteristics with dream anxiety level, Pearson Correlation Analysis was applied. The results were evaluated according to the signifance level of $p<0.05$.

\section{RESULTS}

Seventy OSAS patients including twenty one women and forty nine men aged between twenty five and seventy one with the average age of $49.04 \pm 11.67$ participated in our study. From those, twenty patients including eleven women and nine men aged $53,45 \pm 11,61$ on average formed the ROSAS group while fifty patients including ten women and forty men aged $47.28 \pm 11.33$ on average formed the COSAS group.

\subsection{Comparison of Sociodemographic Data}

Mean ages, genders, marital status, education, employment status, some measures such as length, weight, body mass index, neck circumference and waist circumference belonging to the ROSAS and COSAS patients were compared (Table 1).

It was observed that the average age of ROSAS patients was higher than that of COSAS patients and this difference was found statistically significant $(t=2.04, p=0.05)$.

It was detected that women were dominant in the ROSAS group whereas men were dominant in COSAS group. This difference between genders was found statistically significant $\left(x^{2}=8.33\right.$, $\mathrm{p}<0.05)$.

No significant difference was fixed between marital, educational and employment status of the groups.

Any significant differences between weights, body mass indexes and waist circumferences of the groups were not ascertained. Measures of the length $(t=-2.27, p=0.02)$ and the neck circumference $(t=-2.39, p=0.02)$ in the COSAS group were found higher comparing to those in the ROSAS group and these differences were determined as statistically significant. The details were shown in Table 1.

Table 1. Comparison of sociodemographic characteristics of the groups

\begin{tabular}{|c|c|c|c|c|c|c|c|}
\hline & & \multicolumn{2}{|c|}{$\begin{array}{c}\text { ROUAS } \\
\text { Mean } \pm \text { SD } \\
(n=20)\end{array}$} & \multicolumn{2}{|c|}{$\begin{array}{c}\text { KOUAS } \\
\text { Mean } \pm \text { SD } \\
(n=50)\end{array}$} & \multirow[t]{2}{*}{$t / x^{2}$} & \multirow[t]{2}{*}{$\mathbf{P}$} \\
\hline & & $\mathbf{s}$ & $\%$ & $\mathbf{s}$ & $\%$ & & \\
\hline Age & & \multicolumn{2}{|c|}{$53.45 \pm 11.61$} & \multicolumn{2}{|c|}{$47.28 \pm 11.33$} & 2.04 & $0.05^{*}$ \\
\hline \multirow[t]{2}{*}{ Gender } & Woman & 11 & 52.4 & 10 & 47.6 & 8.33 & $0.00^{*}$ \\
\hline & Man & 9 & 18.4 & 40 & 81.6 & & \\
\hline \multirow[t]{4}{*}{ Marital status } & Single & 1 & 5 & 2 & 4 & 1.98 & 0.57 \\
\hline & Married & 14 & 70 & 42 & 84 & & \\
\hline & Widowed & 2 & 10 & 2 & 4 & & \\
\hline & Divorced & 3 & 15 & 4 & 8 & & \\
\hline \multirow[t]{3}{*}{ Length of education } & Elementary education & 9 & 45 & 23 & 46 & 0.33 & 0.84 \\
\hline & High school & 3 & 15 & 10 & 20 & & \\
\hline & College & 8 & 40 & 17 & 34 & & \\
\hline \multirow[t]{4}{*}{ Employment status } & Out of employ & 27 & 54.00 & 5 & 10 & 2.78 & 0.42 \\
\hline & Employee & 23 & 46.00 & 45 & 90 & & \\
\hline & Self-employed & 1 & 5 & 10 & 20 & & \\
\hline & Retired & 7 & 35 & 17 & 34 & & \\
\hline Height & & 165 & 9.56 & 170 & $66 \pm 7.64$ & -2.27 & $0.02^{*}$ \\
\hline Weight & & 84.7 & 13.60 & 91.1 & $4 \pm 17.82$ & -1.44 & 0.15 \\
\hline Body mass index & & 31.0 & 5.64 & 31.2 & $7 \pm 4.96$ & -0.18 & 0.85 \\
\hline Neck circumference & & 38.9 & 3.85 & 41.4 & $5 \pm 4.04$ & -2.39 & $0.02^{*}$ \\
\hline Waist circumference & & 103 & \pm 11.07 & 109 & $4 \pm 14.65$ & -1.52 & 0.13 \\
\hline
\end{tabular}

SD: Standard Deviation * $P<0.05$ values found statistically significant 


\subsection{Comparison of the Clinical Variables between the Groups}

No significant difference was found between the groups in terms of dream anxiety scale scores $(\mathrm{t}=-0.91, \mathrm{p}=0.36)$ (Table 2).

Any significant differences were not encountered between the groups in terms of Epworth scale scores, either $(t=-0.72, p=0.47)$ (Table 2).

When polysomnographic parameters were compared, no significant difference between the groups was fixed for duration spent in bed, total time analyzed, sleep latency, REM latency, lowest oxygen saturations and the ratios of $\mathrm{N} 1$, N2, N3 sleep phases to total times analyzed. The ratio of REM phase to total time analyzed on percentage basis was found significantly higher in the ROSAS group $(t=3.17, p<0.05)$. Whereas measures of some variables determining severity of the disorder such as arousal index $(\mathrm{t}=-4.95$, $\mathrm{p}<0.05)$, apnea-hypopnea index $(\mathrm{t}=-4.24$, $\mathrm{p}<0,05)$, mean apnea duration $(\mathrm{t}=-2.58, \mathrm{p}=0.01)$, oxygen desaturation index $(\mathrm{t}=-4.36, \mathrm{p}<0.05)$ and periodic limb movement index $(t=-2.92, p<0.05)$ were found significantly higher in the COSAS group compared to those in the ROSAS group (Table 2).

When the effects of gender and age variables previously determined as significantly different between the groups on the dream anxiety levels were investigated by co-variance analysis, any statistically significant effects could not be found (Table 3).

Dream anxiety level was not found significantly related to sleep parameters and epworth sleepiness scale scores (Table 4).

\section{DISCUSSION}

In this study among the OSAS patients we compared dream anxiety levels of the ROSAS patients whose apneas were observed predominantly in the REM phase with the COSAS patients which formed the control group. While doing this, we also investigated differences between the two groups in terms of some sociodemographic and clinical characteristics and probable relations of these characteristics to the dream anxiety.

Table 2. Comparison of clinical characteristics of the groups

\begin{tabular}{|c|c|c|c|c|}
\hline Variables & ROSAS (n=20) & COSAS $(n=50)$ & $\mathbf{t}$ & $\mathbf{p}$ \\
\hline Dream anxiety & $4.8 \pm 7.99$ & $7.4 \pm 9.29$ & -1.09 & 0.27 \\
\hline Epworth & $7.85 \pm 5.97$ & $8.82 \pm 4.68$ & -0.72 & 0.47 \\
\hline Total time analyzed & $413.24 \pm 2287$ & $422.49 \pm 22.98$ & -1.52 & 0.13 \\
\hline Total sleep time & $357.63 \pm 65.56$ & $373.14 \pm 47.59$ & -1.10 & 0.27 \\
\hline Sleep latency & $11.11 \pm 12.33$ & $8.5 \pm 7.69$ & 1.07 & 0.28 \\
\hline REM latency & $128.5 \pm 93.97$ & $153.47 \pm 91.62$ & -1.01 & 0.31 \\
\hline Arousal index & $17.33 \pm 12.47$ & $61.35 \pm 38.76$ & -4.95 & $0.00^{*}$ \\
\hline N1 \% & $3.51 \pm 2.11$ & $4.82 \pm 3.01$ & -1.78 & 0.07 \\
\hline N2 \% & $59.87 \pm 16.16$ & $82.81 \pm 74.08$ & -1.36 & 0.17 \\
\hline N3 \% & $23.36 \pm 15.82$ & $16.25 \pm 18.67$ & 1.49 & 0.13 \\
\hline REM \% & $13.17 \pm 4.57$ & $8.25 \pm 6.28$ & 3.17 & $0.00^{*}$ \\
\hline $\mathrm{AHI}$ & $11.33 \pm 3.82$ & $37.23 \pm 27.04$ & $-4,24$ & $0.00^{*}$ \\
\hline Mean apnea duration & $20.46 \pm 4.29$ & $24.13 \pm 5.72$ & -2.58 & $0.01^{*}$ \\
\hline Lowest oxygen saturation & $81.85 \pm 7.48$ & $77.75 \pm 10.34$ & 1.60 & 0.11 \\
\hline Oksijen desaturation index & $9.63 \pm 4.95$ & $35.73 \pm 26.46$ & -4.36 & $0.00 *$ \\
\hline Periodic limb movements index & $6.01 \pm 11.35$ & $24.10 \pm 26.59$ & -2.92 & $0.00^{*}$ \\
\hline Longest apnea duration & $48.74 \pm 18.2$ & $61.62 \pm 19.93$ & 0.01 & 0.99 \\
\hline
\end{tabular}

Table 3. Effects of age and gender variables on dream anxiety levels

\begin{tabular}{llccccc}
\hline Variables & $\begin{array}{c}\text { Dream anxiety in all } \\
\text { OSAS patients } \\
(\mathbf{n = 7 0})\end{array}$ & $\begin{array}{c}\text { Dream anxiety in } \\
\text { ROSAS patients } \\
(\mathbf{n = 2 0})\end{array}$ & $\begin{array}{c}\text { Dream anxiety in } \\
\text { COSAS patients } \\
(\mathbf{n}=\mathbf{5 0})\end{array}$ \\
\cline { 2 - 7 } & $\mathbf{F}$ & $\mathbf{p}$ & $\mathbf{F}$ & $\mathbf{p}$ & $\mathbf{F}$ & $\mathbf{p}$ \\
\hline Gender & 0.10 & 0.74 & 1.87 & 0.18 & 1.54 & 0.15 \\
Age & 0.42 & 0.51 & 0.72 & 0.70 & 0.31 & 0.58 \\
\hline & &
\end{tabular}


Table 4. Correlation between dream anxiety and sleep parameters

\begin{tabular}{lll}
\hline Dream anxiety & $\mathbf{r}$ & $\mathbf{p}$ \\
\hline Time in bed & $-0,071$ & 0,561 \\
Total sleep time & 0,133 & 0,272 \\
Sleep latency & $-0,070$ & 0,567 \\
REM latency & 0,030 & 0,809 \\
Arousal index & $-0,066$ & 0,585 \\
N1 \% & 0,070 & 0,567 \\
N2 \% & $-0,089$ & 0,465 \\
N3\% & $-0,043$ & 0,725 \\
REM \% & $-0,045$ & 0,711 \\
AHI & $-0,047$ & 0,700 \\
Mean apnea duration & $-0,207$ & 0,088 \\
Lowest oxygen saturation & 0,065 & 0,598 \\
Oksijen desaturation index & 0,022 & 0,858 \\
Periodic limb movements & $-0,057$ & 0,642 \\
Index & & \\
Longest apnea duration & $-0,212$ & 0,078 \\
Epworth & 0,123 & 0,309 \\
\hline \multicolumn{2}{c}{${ }^{*} P<0.05$ values found statistically significant }
\end{tabular}

The mean age of ROSAS patients was found higher than that of COSAS group. In a study in which the effects of age and gender on breathing disorder during sleep related to REM phase were investigated, it was determined that ROSAS had been observed more frequently than COSAS under the age of fifty five in both gender [13]. In another similar study it was found that the incidence frequency of ROSAS was subjected to decrease $10,9 \%$ by each ten years of aging in both genders [14]. Our findings do not fit with these. The limited number of our patients may have been effective in obtaining different results.

It was found that women were dominant in number among ROSAS patients whereas number of men was higher among COSAS patients. In other studies concerning ROSAS, it was found that ROSAS had been more frequently observed in women compared to men $[9,13-15]$. Our findings support those given in the literature.

Whereas there were no differences found between the groups in terms of length, weight, body mass index and waist circumference measurements it was determined that the measurements of neck circumference had been higher in COSAS group compared to ROSAS. It was determined that REM dependent OSAS patients had been more obese $[6,13]$. In the corresponding literature no studies that contain only the difference of neck circumference just as in the case of our study hold place. This situation brings a different approach to the obesity indications and make us to consider that the increasing neck circumference may be a more important risk factor for COSAS in comparison with waist circumference or body mass index.

No differences were found between the groups in terms of Epworth Scale scores used for determining daytime sleepiness states. This finding supports the similar past studies in the literature [15,16]. Complaints of excessive daytime sleepiness frequently observed in OSAS patients may have been resulted from the deterioration of sleep integrity. Our study showed that ROSAS and COSAS patients are equally symptomatic about excessive day time sleepiness complaints.

When the groups were compared to each other in terms of polysomnographic sleep parameters, the indexes of arousal, apnea-hypophnea, oxygene desaturation and periodic limb movements together with the measurements of mean apnea duration in COSAS patients were found higher than those in ROSAS patients. Our study supports the findings of some past studies in which clinical characteristics of ROSAS were investigated. It was reported similarly that ROSAS cases had often had milder obstructive sleep apneas $[9,15,16]$. When considering that these parameters take a determining part in assessing the severity of OSAS, it may be said that the severity of respiratory disorders during sleep in the COSAS patients participated in our research is higher.

In the ROSAS group it has not been found any significant differences in terms of dream anxiety level compared to the other group. There is no study which investigated dream anxiety in obstructive sleep apnea syndrome in the literature. Therefore we discussed our finding on the basis of our comments.

For many years the quality of dreams special to phases has been tried to be determined by evaluating the dream declarations obtained by the way of wakening healthy individuals during REM or NREM phases. Although some researchers defend the opinion that REM and NREM sourced dreams do not bear any differences qualitatively [17], dream declarations have still been being taken from the individuals wakened from the REM sleep mostly $[18,19]$. It has been observed that REM declarations bear intensive emotional content that is longer, vivid, tired and especially formed by fear or anxiety [1]. 
It has been denoted that the existence and the length of REM phase may influence the quality of NREM dreams [20]. In our study we have determined that ROSAS patients spend greater part of their total sleep duration in the REM phase compared to the other groups. The fact that the longer REM phase has not created any difference in the dream anxiety may have resulted from the reasons that the apneas predominantly observed in this phase may generate differences in the emotional content of dreams or cause remembering this type of dreams to be hindered. If we approach to the case from a different point of view, we can claim that this state may have resulted from the fact that dream anxiety levels of COSAS are higher than expected. According to the 'Wakefullness and Recall' model the dream should be followed by a vigilance duration in order to remember its content [21]. In our research we have determined that the arousal index of COSAS group is higher correspondingly. Because of arousals, a rise in the frequency of remembering dreams in the mixed group may also have an effect on increased dream anxiety. Probably this fact might have caused us not to find any differences with the REM dependent group which is determined that they spend greater part of their dreams in the REM phase.

The premier limitation of our research has been insufficiency of the number of patients. The capability of substantiating our hypothesis of this number that we have been able to reach by the patients applied to our outpatient clinic is considerably low.

Our second limitation is the fact that the clinical scales by which we can objectively evaluate existing psychiatric state of the patients have not been applied. Probably we may have left out some personality disorders and psychiatric troubles in the outpatient clinic inspection and these may have affected our results. In the past studies it was indicated that Dream Anxiety Scale scores had increased in some psychiatric tables such as Major Depression [22], Dissociative Disorder [23], Borderline Personality Disorder [24] and in the existence of Childhood Trauma [25]. The basic idea in the 'Continuity Hypothesis' which is one of the theories developed regarding the factors affecting dream recall is that dreams reflect emotional troubles related to wakefulness. It is defended that the factors such as personality characteristics and the effect of wakeful life on dreams loom large in dream declarations [26].
Our third limitation is the fact that Van Dream Anxiety Scale has been developed in the patients suffering from nightmare disorder. Whether this scale can measure the level of dream anxiety in OSAS patients accurately or not is controversial.

Finally, the results may have been affected because the dream anxiety level has not been measured by wakening the patients following the REM phase.

\section{CONCLUSION}

This study guides us to accept dreams as a kind of brain activity during sleep which are affected by the form of sleep. Sleep, wakefulness, dreams and emotions are all the activities that are in relation to each other and created by different mechanisms of the brain. While interpreting dreams from a psychiatric point of view, ignoring the effects of concomitant organic pathologies like sleep disorder will render our comments inadequte.

We suppose that similar studies to be performed in the future getting over our limitations will increase the interest taken in dreams in psychiatry. While planning these studies, we recommend utilizing different scales for evaluation of different characteristics of dreams and using clinical psychiatric scales for evaluating concominant psychiatric disorders objectively.

\section{CONSENT}

As per international standard or university standard, patient's written consent has been collected and preserved by the authors.

\section{ETHICAL APPROVAL}

As per international standard or university standard, written approval of Ethics committee has been collected and preserved by the authors.

\section{ACKNOWLEDGEMENT}

We thank the staff of the Sleep Disorders Clinics of Erenkoy Neurolopsychiatric Diseases Education and Research Hospital.

\section{COMPETING INTERESTS}

Authors have declared that no competing interests exist. 


\section{REFERENCES}

1. Hobson JA, Pace-Schott EF, Stickgold R. Dreaming and the brain: Toward a cognitive neuroscience of conscious states. The Behavioral and Brain Sciences. 2000;23(6):793-842:discussion 904-1121.

2. Moorcroft WH. Understanding sleep and dreaming. New York: Springer Science; 2005.

3. Cipolli C, Ferrara M, De Gennaro L, Plazzi G. Beyond the neuropsychology of dreaming: Insights into the neural basis of dreaming with new techniques of sleep recording and analysis. Sleep Medicine Reviews; 2016.

4. Young T, Peppard PE, Gottlieb DJ. Epidemiology of obstructive sleep apnea: A population health perspective. American Journal of Respiratory and Critical Care Medicine. 2002;165(9):1217-39.

5. De Groen JH, Op den Velde W, Hovens JE, Falger PR, Schouten EG, van Duijn $H$. Snoring and anxiety dreams. Sleep. 1993;16:35-6.

6. Schredl M, Schmitt J, Hein G, Schmoll T, Eller S, Haaf J. Nightmares and oxygen desaturations: Is sleep apnea related to heightened nightmare frequency? Sleep \& Breathing = Schlaf \& Atmung. 2006; 10(4):203-9.

7. Fisher S, Lewis KE, Bartle I, Ghosal R, Davies L, Blagrove M. Emotional content of dreams in obstructive sleep apnea hypopnea syndrome patients and sleepy snorers attending a sleep-disordered breathing clinic. Journal of clinical sleep medicine: JCSM: Official publication of the American Academy of Sleep Medicine. $2011 ; 7(1): 69-74$.

8. The AASM manual for the scoring of sleep and associated events: Rules, terminology, and technical specification; 2007.

9. O'Connor C, Thornley KS, Hanly PJ. Gender differences in the polysomnographic features of obstructive sleep apnea. American Journal of Respiratory and Critical Care Medicine. 2000;161(5):1465-72.

10. Johns MW. A new method for measuring daytime sleepiness: The Epworth sleepiness scale. Sleep. 1991;14(6):540-5.

11. Agargun MY, Cilli AS, Kara $H$, Bilici M, Telcioglu M, Semiz UB, et al. Epworth Uykululuk Olcegi'nin Gecerliligi ve Guvenilirligi. Turk Psikiyatri Dergisi. 1999; 10:261-7.
12. Agargun $M Y$, Kara $H$, Bilici $M$, Çilli AS, Telci M, Semiz ÜB, et al. The van dream anxiety scale: The subjective measure of dream anxiety in nightmare sufferers. Sleep and Hypnosis. 1999; 4:204-11.

13. Koo BB, Dostal J, loachimescu O, Budur $K$. The effects of gender and age on REMrelated sleep-disordered breathing. Sleep \& breathing $=$ Schlaf \& Atmung. 2008; 12(3):259-64.

14. Koo BB, Patel SR, Strohl K, Hoffstein V. Rapid eye movement-related sleepdisordered breathing: Influence of age and gender. Chest. 2008;134(6):1156-61.

15. Conwell W, Patel B, Doeing D, Pamidi S, Knutson KL, Ghods F, et al. Prevalence, clinical features, and CPAP adherence in REM-related sleep-disordered breathing: A cross-sectional analysis of a large clinical population. Sleep \& breathing = Schlaf \& Atmung. 2012;16(2):519-26.

16. Campos-Rodriguez F, Fernandez-Palacin A, Reyes-Nunez N, Reina-Gonzalez A. Clinical and polysomnographic features of rapid-eye-movement-specific sleepdisordered breathing. Archivos de Bronconeumologia. 2009;45(7):330-4.

17. Antrobus J. REM and NREM sleep reports: comparison of word frequencies by cognitive classes. Psychophysiology. 1983;20(5):562-8.

18. Fosse R, Stickgold R, Hobson JA. Brainmind states: Reciprocal variation in thoughts and hallucinations. Psychological science. 2001;12(1):30-6.

19. Nielsen TA. A review of mentation in REM and NREM sleep: "covert" REM sleep as a possible reconciliation of two opposing models. The Behavioral and brain sciences. 2000;23(6):851-66;discussion 904-1121.

20. Suzuki $H$, Uchiyama $M$, Tagaya $H$, Ozaki A, Kuriyama K, Aritake S, et al. Dreaming during non-rapid eye movement sleep in the absence of prior rapid eye movement sleep. Sleep. 2004;27(8):148690.

21. Koulack D, Goodenough DR. Dream recall and dream recall failure: An arousal retrieval model. Psychological Bulletin. 1976;83:975-84.

22. Bilici M, Yazıcı K, Ozer OA, Kavakçı O. Dream anxiety level in patients with major depression. Sleep and Hypnosis. 2002; 4:15-21. 
23. Agargun MY, Kara H, Ozer OA, Selvi $\mathrm{Y}$, Kiran U, Ozer B. Clinical importance of nightmare disorder in patients with dissociative disorders. Psychiatry and Clinical Neurosciences. 2003;57(6):575-9.

24. Semiz UB, Basoglu C, Ebrinc S, Cetin M. Nightmare disorder, dream anxiety and subjective sleep quality in patients with borderline personality disorder. Psychiatry and Clinical Neurosciences. 2008; 62(1):48-55.
25. Agargun MY, Kara $\mathrm{H}$, Ozer OA, Selvi $\mathrm{Y}$, Kiran U, Kiran S. Nightmares and dissociative experiences: The key role of childhood traumatic events. Psychiatry and Clinical Neurosciences. 2003;57(2):13945.

26. Schredl M. Do sleep disorders affect the dreaming process? Dream recall and dream content in patients with sleep disorders. Sleep Med Clin. 2010;5:193202.

(c) 2017 Yazla et al.; This is an Open Access article distributed under the terms of the Creative Commons Attribution License (http://creativecommons.org/licenses/by/4.0), which permits unrestricted use, distribution, and reproduction in any medium, provided the original work is properly cited.

Peer-review history:

The peer review history for this paper can be accessed here: http://sciencedomain.org/review-history/19254 